\title{
Intoxicação por selênio em suínos no Sul do Brasil ${ }^{1}$
}

\author{
Danilo C. Gomes ${ }^{2}$, Suyene O. Souza ${ }^{2}$, Gregory D. Juffo², Saulo P. Pavarini² \\ e David Driemeier ${ }^{2 *}$
}

\begin{abstract}
Gomes D.C., Souza S.O., Juffo G.D., Pavarini S.P. \& Driemeier D. 2014. [Selenium poisoning in swine in southern Brazil.] Intoxicação por selênio em suínos no Sul do Brasil. Pesquisa Veterinária Brasileira 34(12):1203-1209. Setor de Patologia Veterinária, Faculdade de Veterinária, Universidade Federal do Rio Grande do Sul, Av. Bento Gonçalves 9090, Porto Alegre, RS 91540-000, Brazil. E-mail: davetpat@ufrgs.br

Two outbreaks of poisoning by selenium in swine in southern Brazil are described. Piglets were affected in the post-weaning period, between 27 and 22 days, with mortality rates ranging from $16 \%$ to $15.3 \%$ (Outbreak 1 and 2 respectively). The pigs had focal symmetrical poliomielomalacia and hoof lesions, which were initially characterized by a reddish line at the coronary band that evolved in surviving pigs to release of the hooves. Clinical signs were observed after six days (Outbreak 1) and 30h (Outbreak 2) after the introduction of feed with high selenium content. The appearance of the signs was abrupt, characterized by gait and progressing to paralysis of the hind limbs and later to tetraparesis. Macroscopically, in some animals there were yellow circular foci with darker areas restricted to the ventral horn of the gray matter in the cervical and lumbar intumescence. Microscopically, these areas correspond to gray matter malacia, characterized by microcavitation, neuronal loss, chromatolysis, neuronophagia, infiltrating Gitter cells, microgliosis, Alzheimer's type II astrocytes and proliferation of endothelial cells which were labeled by immunohistochemistry (IHC) as von Willebrand factor. Also in the second outbreak, two pigs showed diffuse vacuolation of the cytoplasm of neurons and in one pig gemistocytic astrocytes were observed. In IHC for GFAP astrocytosis and astrogliosis was observed. Besides those spinal changes in two pigs symmetrical polioencephalomalacia in the brainstem was found. In feed samples, 3.38ppm (Outbreak 1) and 154ppm (Outbreak 2) of Se/kg were detected, and in liver samples higher dosages than 3.34ppm (range from 3.34 to $10 \mathrm{ppm}$ ) were found. In Outbreak 2, 44 days after the withdrawal of the diet, the euthanasia of six pigs was performed to monitor liver selenium levels (two controls and four surviving pigs per outbreak); all had normal levels of selenium in the liver.
\end{abstract}

INDEX TERMS: Selenium poisoning, swine, focal symmetrical poliomyelomalacia, hoof lesions.

RESUMO.- São descritos dois surtos de intoxicação por selênio em suínos na região Sul do Brasil. Foram acometidos leitões em fase de creche, entre 27 e 22 dias, com mortalidade variando de $16 \%$ a $15,3 \%$ (Surto 1 e 2 respectivamente). Os suínos apresentaram poliomielomalacia simétrica focal e lesões de casco, que inicialmente eram caracterizadas por uma linha avermelhada na borda coronária que evoluía nos suínos sobreviventes para desprendimento do casco. Os si-

\footnotetext{
${ }^{1}$ Recebido em 4 de agosto de 2014.

Aceito para publicação em 8 de dezembro de 2014.

2 Departamento de Patologia Clínica Veterinária, Faculdade de Veterinária, Universidade Federal do Rio Grande do Sul (UFRGS), Av. Bento Gonçalves 9090, Porto Alegre, RS 95320-000, Brasil. *Autor para correspondência: davetpat@ufrgs.br
}

nais clínicos iniciaram após seis dias (Surto 1) e 30 horas (Surto 2) da introdução da ração com alto teor de selênio. 0 surgimento dos sinais foi abrupto, caracterizado por andar cambaleante, com evolução para paralisia dos membros pélvicos e posteriormente tetraparesia. Macroscopicamente observaram-se focos circulares amarelados com áreas deprimidas mais escuras, restritas ao corno ventral da substância cinzenta em intumescências cervical e lombar. Microscopicamente essas áreas corresponderam à malacia da substância cinzenta, caracterizada por microcavitações, perda neuronal, cromatólise, neuronofagia, infiltrado de células Gitter, microgliose, astrócitos de Alzheimer tipo II e proliferação de células endoteliais evidenciadas na imunohistoquímica (IHQ) para fator de von Willebrand. Ainda, 
no segundo surto, dois animais apresentaram vacuolização difusa do citoplasma de neurônios e em um suíno foram observados astrócitos gemistocíticos. Na IHQ para GFAP ficou evidenciada uma astrocitose e astrogliose. Além dessas alterações medulares, em dois suínos observou-se, polioencefalomalácia simétrica no tronco encefálico. Em amostras de ração, detectou-se 3,38ppm (Surto 1) e 154ppm (Surto 2) de Se/kg e em amostras de fígado foram encontradas dosagens superiores a 3,34ppm (variando de 3,34 até $10 \mathrm{ppm}$ ). No Surto 2, após 44 dias da retirada da ração, foi realizada eutanásia de seis suínos para monitoramento de níveis hepáticos de selênio (dois suínos controles e quatro sobreviventes ao surto) e todos apresentaram níveis normais de selênio no fígado.

TERMOS DE INDEXAÇÃO: Intoxicação por selênio, suínos, poliomielomalácia simétrica focal, lesões de casco.

\section{INTRODUÇÃO}

0 selênio (Se) é um microelemento essencial usado em rações animais (Moreno et al. 2007). Pode ser encontrado em rochas, arenitos, carvão, solo, água de superfície e vegetação (Fan \& Kizer 1990). Após a descoberta dos efeitos benéficos capazes de reduzir a peroxidação das membranas celulares, o Se passou a ser incluído em suplementos minerais, aumentando os riscos de intoxicação para os animais e o homem, uma vez que há uma pequena diferença entre as doses, terapêutica e tóxica (Oliveira et al. 2007).

Quadros de intoxicação decorrem geralmente da ingestão excessiva do elemento, devido a erros na formulação ou homogeneização de rações, pesagem errada do premix (Schultz \& Hoffmann 1995) e utilização de aditivos com níveis elevados de selênio (Moreno et al. 2007). A doença ocorre, principalmente, em suínos jovens, entre um e cinco meses de idade. São descritas três apresentações clínicas distintas desta enfermidade: dificuldades locomotoras com paresia dos membros e tetraparesia, resultantes de poliomielomalácia simétrica focal (Wilson et al. 1983, Carson 2006); lesões de pele e separação da borda coronária dos cascos (Mahan \& Moxon 1984, Banholzer \& Heinrtzi 1998, Hélie et al. 1998); e perdas reprodutivas caracterizadas por diminuição da concepção e natimortos (Carson 2006). Em alguns surtos foram descritas as lesões nos cascos concomitante as lesões medulares (Harrison et al. 1983, Castell et al. 1985, Casteignau et al. 2006). Este trabalho tem por objetivo relatar dois surtos de intoxicação por selênio em suínos no Sul do Brasil, caracterizando as alterações clínicas, patológicas e imuno-histoquímicas.

\section{MATERIAL E METÓDOS}

Dados epidemiológicos e clínicos foram obtidos junto ao proprietário e ao veterinário responsável pela granja em visitas à propriedade. Durante o Surto 1 amostras de tecidos de um animal (Suíno 1) foram enviadas ao Setor de Patologia Veterinária (SPV) da Universidade Federal do Rio Grande do Sul (UFRGS), já fixadas em solução de formalina tamponada a 10\%, para análise histopatológica. A partir da suspeita obtida foi realizada visita a propriedade e sete suínos foram necropsiados (Suínos 2-8). No Surto 2, três suínos (Suínos 9-11) com aproximadamente 22 dias de idade foram encaminhados ao SPV da UFRGS para necropsia.
Foi realizada uma visita à propriedade 23 dias após o inicio do fornecimento da ração contaminada para avaliação dos animais sobreviventes e coleta de informações adicionais. Após 44 dias do inicio do consumo da ração contaminada foi feita uma segunda visita à propriedade com coleta de amostras de seis animais, sendo estas amostras coletadas de quatro que sobreviveram ao Surto 2 (Suínos 12-15) e dois controles que não haviam ingerido a ração (Suínos 16 e 17).

Amostras de tecidos foram colhidas de ambos os surtos em solução de formalina tamponada a $10 \%$ e processadas rotineiramente para exame histopatológico e coradas pela hematoxilina e eosina (HE). Adicionalmente fragmentos de sistema nervosos central foram corados pela coloração de ácido periódico de Schiff (PAS). Cortes de medula espinhal (regiões cervical, intumescência cervical, torácica, lombar e intumescência lombar) e cortes do encéfalo (córtex frontal, cerebelo, tálamo, corpo estriado, colículo rostral e caudal, pedúnculo cerebelar, ponte e óbex) foram preparados em lâminas positivadas (ImmunoSlide-EasyPath ${ }^{\circledR}$ ) e fixados em estufa a $60^{\circ} \mathrm{C}$ por três horas para a técnica de imuno-histoquímica pelo método da streptavidina-biotina ligada a peroxidase. Os anticorpos primários utilizados foram: anti-proteína ácida fibrilar glial (GFAP - diluição de 1:500), anti-proteína S100 (S-100 - diluição 1:200) e anti-fator de von Willebrand (diluição 1:800). Inicialmente a peroxidase endógena foi inibida por peroxido de hidrogênio a $10 \%$ por 10 minutos. Para a recuperação antigênica, utilizou-se solução de TRIS EDTA pH 9,0 por 10 minutos, em panela de pressão a $100^{\circ} \mathrm{C}$ (GFAP), solução de tampão citrato pH 6,0 em panela de pressão a $100^{\circ} \mathrm{C}$ por 20 minutos (S-100) e 3 minutos em panela de pressão à $125^{\circ} \mathrm{C}$ (fator de von Willebrand). As lâminas foram incubadas em câmara úmida "overni$g h t^{\prime \prime}$ a $4 \stackrel{\circ}{ } \mathrm{C}$ e reveladas com DAB (GFAP e Fator de von Willebrand) e VECTOR ${ }^{\circledR}$ NovaRED (S-100).

Amostras de fígado de 14 animais (Suínos 4-17) e da ração do Surto 2 foram encaminhadas refrigeradas para dosagem de selênio pelo método de espectrometria atômica quantitativa. Amostras de ração do Surto 1 foram encaminhadas para a dosagem de Se pelo método de absorção atômica em forno de grafite.

\section{RESULTADOS}

Em janeiro de 2010, leitões de dois lotes de uma granja localizada no município de Cruzeiro do Iguaçu/PR (Surto 1), apresentaram quadro de paralisia. Inicialmente, 36 suínos de um total de 120 morreram. Eles apresentaram quadro de paralisia seis dias após entrada na creche (Fig.1). Após estes quadros de paralisia, o proprietário suspendeu o fornecimento da ração e, após a troca por outra remessa, observou diminuição do problema. Posteriormente, o proprietário optou por adicionar antibiótico e inativador de micotoxina à ração problema e fornecê-la ao novo lote de 100 suínos que seriam desmamados. Após seis dias de consumo desta ração 16 leitões deste lote, com idade aproximada de 27 dias, apresentaram quadros de paralisia e acabaram morrendo. Os suínos afetados permaneciam sentados, com paralisia dos membros pélvicos, que ficavam afastados lateralmente e alguns animais adotavam a "posição de cão sentado". Alguns suínos apresentaram tetraparesia, e todos mantiveram o estado de alerta e temperatura em torno de $39^{\circ} \mathrm{C}$. Deste lote foram necropsiados seis suínos (Suínos 2-7). Nos suínos 4-7 foi observado nos cascos uma linha avermelhada na borda coronária (Fig.2A). Os suínos que haviam sobrevivido ao primeiro surto (total de 16 animais), aos 50 dias de idade, apresentaram dificuldade 


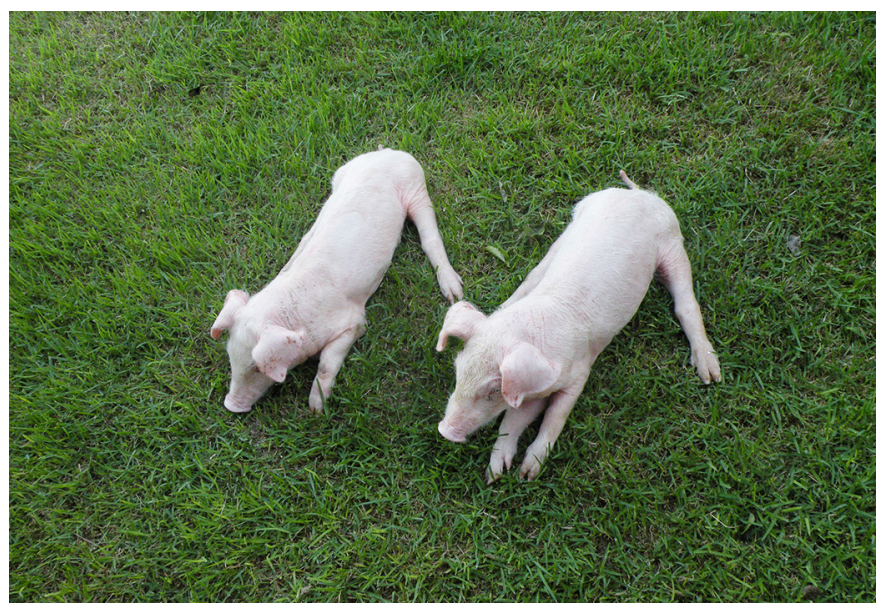

Fig.1. Intoxicação por selênio em suínos. Suínos em fase de creche, com paralisia dos membros pélvicos.

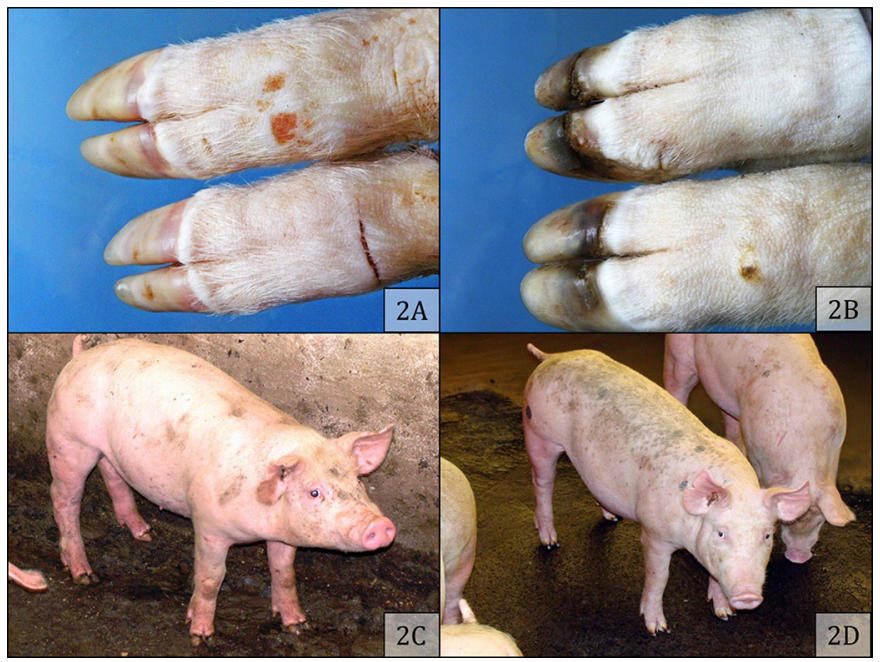

Fig.2. Intoxicação por selênio em suínos. (A) Suíno 4, seis dias após ingestão de ração com excesso de selênio. Linha avermelhada na borda coronária do casco do membro torácico direito. (B) Suíno 8, após 23 dias de retirada da ração com excesso de selênio (Se). Desprendimento do casco na borda coronária. (C) Suíno 8 após 23 dias de retirada da ração com excesso de Se. Linha enegrecida no casco distal a borda coronária. (D) Suíno 14, após 44 dias da retirada da ração com excesso de Se. Observa-se linha enegrecida mais distal da borda coronária com desprendimento.

locomotora, andar sobre a ponta dos cascos, leves tremores musculares e decúbito frequente. Nesses suínos foram observados graus variados de desprendimento do casco na borda coronária (Fig.2B). Um suíno (Suíno 8) desse grupo, que apresentava dificuldade locomotora acentuada, foi eutanasiado e necropsiado.

Em uma granja de suínos próximo à cidade de Dois Vizinhos/PR, durante o mês de março de 2011 (Surto 2), 24 horas após a introdução de uma nova partida da ração, o proprietário notou que os leitões de um lote na fase de creche (2285 suínos de 22 dias de idade) ingeriram menos ração que o esperado. Após 30 horas do fornecimento da ração 350 leitões do lote apresentaram sinais de paralisia flácida dos membros pélvicos, seguida de paralisia flácida dos membros torácicos, decúbito lateral, bradipneia, insufi- ciência respiratória, agonia e morte. A ração foi retirada do consumo dos suínos no dia seguinte. Seis dias após a introdução da nova ração, três animais (Suínos 9-11) que ainda apresentavam sinais clínicos, foram eutanasiados e necropsiados. Em visita realizada à propriedade, posteriormente as necropsias, foi observado nos suínos sobreviventes ao surto (23 dias após início da ingestão da ração) apenas uma linha avermelhada na borda coronária dos cascos e outros com lesões de coloração enegrecida na borda coronária com separação dos mesmos (Fig.2C). Após 44 dias do inicio da ingestão da ração foi realizada outra visita a propriedade e foi observado que os suínos apresentavam leve claudicação e uma linha enegrecida nos cascos, distal a borda coronária (Suínos 12-15) (Fig.2D).

Na medula espinhal dos Suínos 2, 3, 7 e 9-11, havia áreas circulares deprimidas de aproximadamente $0,2 \mathrm{~cm}$ de diâmetro, levemente amareladas a esbranquiçadas no corno ventral do $\mathrm{H}$ medular das intumescências cervicais e lombares (Fig.3).

Lesões microscópicas foram encontradas na medula espinhal de todos os suínos, principalmente nas intumescências cervical e lombar; somente dois animais apresentaram lesão na região do tronco encefálico (Suíno 8 e 11). Em cinco casos, a lesão era mais severa na intumescência lombar (Suínos 1-3, 10 e 11), em dois na intumescência cervical (Suínos 4 e 5) e, em dois casos não havia diferença entre a severidade da lesão nas intumescências (Suínos 6, 7 e 9). No suíno 8, toda a extensão da medula estava afetada mas estas lesões eram mais acentuadas na porção cervical da medula. As lesões medulares eram encontradas, exclusivamente, na substância cinzenta do corno ventral do $\mathrm{H}$ medular e eram caracterizadas por áreas com vacuolização do neurópilo no interior da lesão e, principalmente, na sua periferia, formando microcavitações (Fig.4A); havia neurônios com aumento de volume e pericário arredondado. A substância de Nissl estava mais dispersa na periferia do que na porção central (cromatólise periférica) e, por vezes, com o desaparecimento total da substancia de Nissl (cromatólise total) (Fig.4B). Os núcleos, por vezes, estavam deslocados para periferia, ou mesmo ausentes; havia neurônios

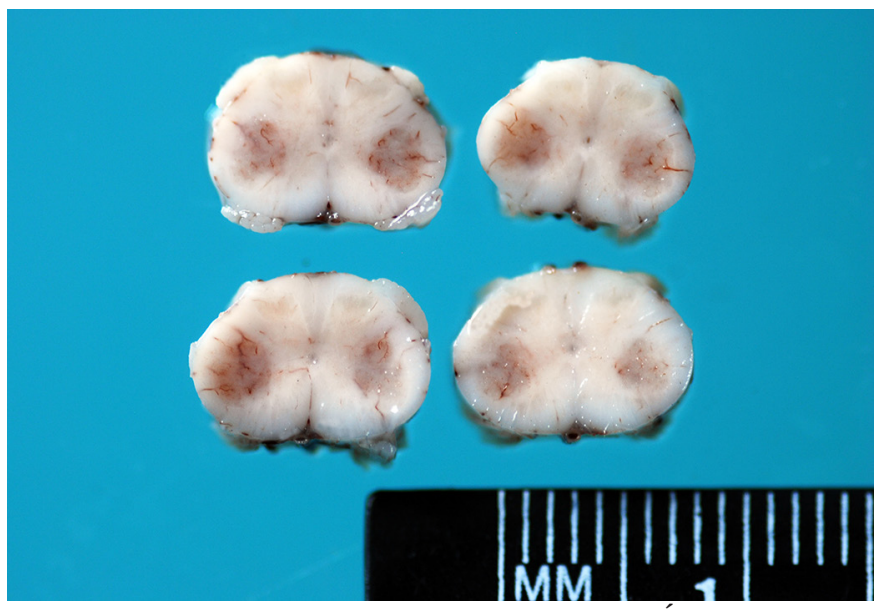

Fig.3. Intoxicação por selênio. Surto 2. Suíno 11. Áreas circulares amareladas de aproximadamente $0,2 \mathrm{~cm}$ de diâmetro no corno ventral do $\mathrm{H}$ medular. 

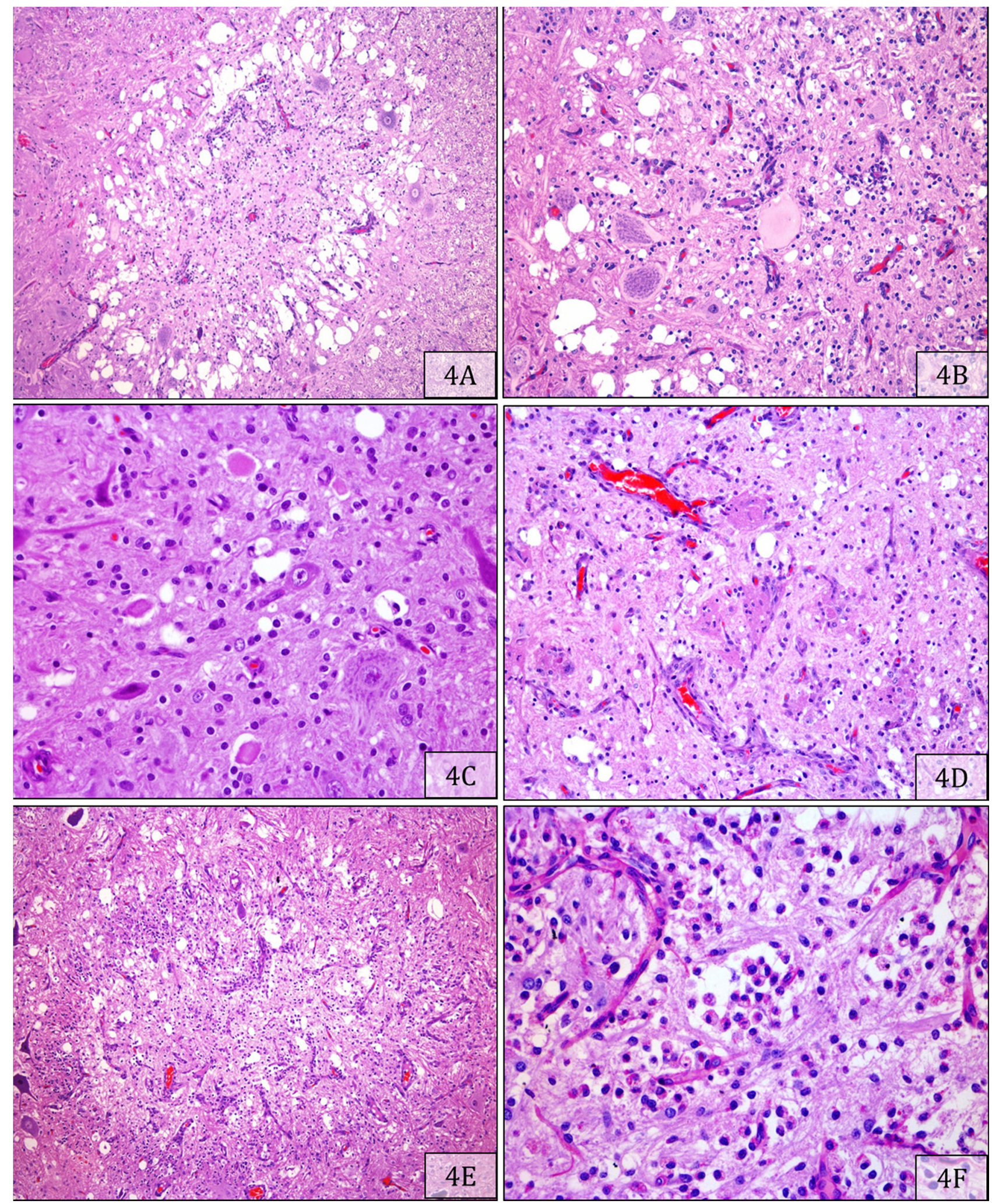

Fig.4. Intoxicação por selênio. (A) Suíno 7. Intumescência lombar. Microcavitações, perda neuronal, microgliose e proliferação de células endoteliais no corno ventral do H medular. HE, obj.10x. (B) Suíno 6. Intumescência lombar. Neurônio aumentado de volume, contorno citoplasmático levemente arredondado e substância de Nissl dispersa na periferia (Cromatólise periférica), nota-se também um neurônio com citoplasma eosinofílico e com ausência da substância de Nissl e núcleo(Cromatólise total). HE, obj.20x. (C) Suíno 4. Intumescência lombar, neurônio com citoplasma eosinofílico e núcleo picnótico, com bordos citoplasmáticos retraídos. HE, obj.40x. (D) Suíno 11. Intumescência lombar. Neurônios com citoplasma eosinofílico, cercados por células da glia (neuronofagia). HE, obj.20x.

(E) Suíno 2. Intumescência cervical. Corno ventral com gliose, proliferação endotelial e discreta vacuolização. HE, obj.10x. (F) Suíno 2. Intumescência lombar, infiltrado de macrófagos com citoplasma abundante e eosinofílico. Ácido periódico de Schiff (PAS), obj.40x. 
diminuídos de tamanho, sem núcleo e com citoplasma levemente eosinofílico e homogêneo (Fig.4C), muitas vezes, cercados por células da glia e havia neurônios fragmentados com infiltrado de macrófagos (neuronofagia) (Fig.4D) além de perda neuronal na região. Nos Suínos 10 e 11 foi observada grande quantidade de neurônios extremamente grandes, com citoplasmas volumosos, eosinofílicos com leve vacuolização difusa e alguns com neuronofagia. Havia ainda microgliose (Fig.4E) e variável quantidade de células Gitter (com grânulos citoplasmáticos evidenciados pela coloração de PAS) (Fig.4F). Nos Suínos 9 e 11 foi observado infiltrado multifocal leve de eosinófilos. Observou-se ainda uma proliferação vascular nos focos de lesão, evidenciadas na imuno-histoquímica para fator de von Willebrand.

Em alguns suínos foram evidenciadas astrogliose e astrocitose no foco da lesão com auxilio da técnica de imuno-histoquímica para GFAP. Em um caso (Suíno 8) foram observados astrócitos com citoplasma abundante, eosinofílico e núcleo excêntrico (gemistócitos). Foram observados também astrócitos com tumefação nuclear, cromatina dispersa e nucléolos proeminentes, esses dispostos isoladamente ou em duplas ou trios (astrócitos de Alzheimer tipo II), que foram positivos na IHQ para proteína S100 e negativos para GFAP. Observou-se ainda hemorragia multifocal discreta (Suínos 1, 2, 6, 9 e 10). No suíno 8 estavam também afetadas as porções da medula cervical e torácica, estas formavam pontes unindo os dois cornos ventrais. As lesões no tronco encefálico observadas nos Suínos 8 e 11 eram semelhantes as lesões medulares com envolvimento das formações reticulares (Suíno 8), os núcleos vermelhos do colículo rostral e o núcleo motor do nervo trigêmeo do pedúnculo cerebelar (Suíno 11). Ocasionalmente observou-se na substância branca adjacente à lesão discreta a moderada degeneração Walleriana com esferoides axonais. Os Suínos 12-17 não apresentaram lesões microscópicas no sistema nervoso central.

Histologicamente as lesões de casco inicialmente eram de vacuolização do epitélio basal e desprendimento do mesmo. Nos casos mais crônicos observou-se ausência completa do epitélio com infiltrado de neutrófilos íntegros e degenerados, além de crostas vegetais aderidas a superfície.

$\mathrm{O}$ resultado da dosagem de selênio nos fígados dos $\mathrm{Su}-$ ínos 4-17 estão representados no Quadro 1. A dosagem de

Quadro 1. Intoxicação por Selênio. Surto 1 e 2. Dosagem de selênio em amostras de fígados refrigerados

\begin{tabular}{cc}
\hline Animal & Dosagem de Selênio mg Se $/ \mathrm{kg}$ \\
\hline Suíno 4 & 3,34 \\
Suíno 5 & 4,70 \\
Suíno 6 & 10,0 \\
Suíno 7 & 3,84 \\
Suíno 8 & 4,0 \\
Suíno 9 & 7,11 \\
Suíno 10 & 10,0 \\
Suíno 11 & 5,42 \\
Suíno 12 & 1,53 \\
Suíno 13 & 1,35 \\
Suíno 14 & 1,48 \\
Suíno 15 & 1,45 \\
Suíno 16 & 1,42 \\
Suíno 17 & 1,73
\end{tabular}

selênio na ração fornecida aos suínos foi de 3,9mg de Se/kg (Surto 1) e 154mg de Se/kg (Surto 2).

\section{DISCUSSÃO}

O diagnóstico de intoxicação por selênio nos suínos desse estudo foi baseado no conjunto de dados epidemiológicos, clínicos, patológicos e na detecção de altos níveis do microelemento na ração e em amostras de fígado dos suínos afetados. Os achados clínicos e patológicos dos surtos aqui descritos são compatíveis com os casos de intoxicação espontânea e experimental por selênio em suínos (Harrison et al. 1983, Wilson et al. 1983, 1988, 1989, Castell et al. 1985, Saford 1990, Stowe et al. 1992, Schultz \& Hoffmann 1995, Panter et al. 1996, Penrith \& Robinson 1996, Banholzer \& Heinritzi 1998, Davidson-York et al. 1999, Casteignau et al. 2006, Nathues et al. 2010). Os achados histológicos sugerem um diagnóstico provável de intoxicação por selênio, pois o excesso de ingestão de selênio é a única causa conhecida de poliomielomalácia simétrica focal em suínos (Wilson et al. 1983, 1988).

De acordo com alguns autores (Mahan \& Moxon 1984, Kim \& Mahan 2001, Carson 2006), o nível mínimo necessário para causar intoxicação é de 5 ppm na ração, com desenvolvimento de quadros crônicos com lesões nos cascos e na pele dos suínos. Para o aparecimento de lesões medulares se faz necessário o mínimo de, 10 ppm de selênio na ração (Carson 2006). O baixo nível de selênio encontrado na ração do Surto $1(3,9 \mathrm{ppm})$ possivelmente, pode ser atribuido a uma distribuição não homogênia do microelemento na ração, levando os animais a ingerirem grandes quantidades de selênio.

Nos suínos com poliomielomalácia simétrica focal deste estudo, os níveis de selênio eram superiores a 3,34ppm no fígado. 0 menor nível considerado tóxico é 3ppm em amostras de fígado e rim (Carson 2006). Após 42 dias da retirada da ração os suínos que não morreram apresentaram níveis hepáticos de selênio inferiores a 1,73ppm, o que difere dos achados de Davidson-York et al. (1999) que, após 72 dias da retirada da ração com excesso de selênio, ainda detectaram um animal com nível de 3,3ppm de Se no fígado. Não foi observada correlação entre altos níveis de selênio no fígado e a severidade das lesões histológicas, dados semelhantes aos encontrados na literatura (Panter et al. 1996, Davidson-York et al. 1999). A porcentagem de animais com paralisia nos surtos variou de 15 a 16\%, dados semelhantes já foram descritos (Davidson-York et al. 1999). Todavia outros trabalhos já demostraram mortalidades menores $(2,8 \%)$ (Harrison et al. 1983) e maiores (100\%) (Nathues et al. 2010).

Os sinais clínicos descritos em ambos os surtos são semelhantes aos descritos por outros autores. Esses eram caracterizados por surgimento abrupto de ataxia dos membros pélvicos, rigidez, progressão para paresia, tetraparesia, decúbito, ausência de febre, estado de alerta inalterado e ingestão normal de comida e água (Harrison et al. 1983, Wilson et al. 1983, 1988, Casteel et al. 1985, Stowe et al. 1992, Summers et al. 1995, Penrith \& Robinson 1996, Carson, 2006, Casteignau et al. 2006, Nathues et al. 2010). A paresia e a paralisia observadas nos suínos podem estar relacionadas às lesões simétricas presentes nos cornos ventrais da medula espinhal, principalmente, nas intumescências cervical e lombar, as quais são associadas a paralisia de neurônio motor inferior (De Lahun- 
ta 2009). Outros sinais como depressão, dispneia e andar rígido com arrastamento de pinças observados em alguns animais desses surtos também já foram relatados em outros trabalhos (Stowe et al. 1992, Penrith \& Robinson 1996). A redução no consumo demonstrada pelos suínos do segundo surto também foi observada em animais com altos níveis de selênio na ração (Mahan \& Moxon 1984, Sanford 1990, Penrith \& Robinson 1996, Hélie et al. 1998, Kim \& Mahan 2001).

0 inicio das alterações clinicas após o consumo da ração variou de um dia a seis dias. 0 início da manifestação neurológica é variado, e depende da concentração, da quantidade ingerida, da duração da exposição e da fonte de origem do selênio. São relatados surtos após até seis semanas da introdução da ração (Casteel et al. 1985). Em contra partida outros estudos demonstram o aparecimento de sinais clínicos em um curto intervalo de tempo (Nathues et al. 2010). Sabe-se que o selênio inorgânico produz lesões mais rápidas e mais severas do que o selênio orgânico, porém este último apresenta maior armazenamento em órgãos (Panter et al. 1996).

Os achados macroscópicos na medula espinhal e nos cascos são similares aos descritos por outros estudos. Quando presentes, as lesões podais são caracterizadas inicialmente por um avermelhamento na borda coronária, que se torna enegrecida e posteriormente há o desprendimento do casco (Harrison et al. 1983, Casteel et al. 1985, Banholzer \& Heinritzi 1998, Hélie et al. 1998, Davidson-York et al. 1999, Kim \& Mahan 2001, Casteignau et al. 2006). As lesões medulares são confinadas às intumescências (Harrison et al. 1983, Sanford 1990), porém em animais com evolução mais crônica podem ser observadas em outros segmentos da medula espinhal, como observado no suíno 8. Desta forma o exame macroscópico da medula deve ser feito com atenção, sendo importante examinar todos os segmentos medulares, especialmente as intumescências cervical e lombar.

Além da poliomielomalácia simétrica focal pode se observar ao exame histológico polioencefalomalácia simétrica focal, com lesão em núcleo motor de trigêmeo e facial, núcleos cuneiformes e grácil, formações reticulares e, ocasionalmente, em núcleo pontino, núcleo olivar, colículo caudal e núcleo cerebelar (Harrison et al. 1983, Wilson et al. 1983, Summers et al. 1995, Casteignau et al. 2006, Nathues et al. 2010). Foram encontradas alterações em formação reticular da ponte (Suíno 8), núcleos vermelhos do colículo rostral e núcleo motor do nervo trigêmeo do pedúnculo cerebelar (Suíno 11) do tronco encefálico.

Alguns autores descrevem lesões mais severas em intumescência lombar do que na intumescência cervical (Harrison et al. 1983, Wilson et al. 1983, 1988, Casteel et al. 1985, Sanford 1990, Stowe et al. 1992, Penrith \& Robinson 1996, Davidson-York et al. 1999). No presente estudo a intensidade das lesões nas intumescências variou, com cinco casos mais acentuados na intumescência lombar, dois na intumescência cervical e três casos sem diferença na intensidade entre essas duas regiões.

Microscopicamente os eventos iniciais aparentemente são a vacuolização do neurópilo, degeneração e necrose de células da glia e tumefação e ativação endotelial, acompanhadas por alterações cromatolíticas em neurônios moto- res. A proliferação endotelial é proeminente no neurópilo necrótico, e macrófagos aparecem e transformam-se em células Gitter. Um infiltrado de poucos eosinófilos é comum (Wilson et al. 1983, Summers et al. 1995). Os achados microscópicos encontrados em ambos os surtos são semelhantes aos descritos acima.

A vacuolização difusa do citoplasma de neurônios observada em dois animais, não foi até então relatada em animais intoxicados por selênio. Os neurônios são as células mais sensíveis do sistema nervoso central, vacúolos podem estar relacionados à resposta neuronal frente a uma lesão. A necrose neuronal é caracterizada por degeneração hidrópica, tumefação de mitocôndrias, picnose e fragmentação do núcleo e lise celular (Zachary 2009). Os vacúolos foram encontrados em neurônios com aumento de tamanho e citoplasma levemente eosinofílico. Essa vacuolização caracteriza uma fase inicial da lesão neuronal. A cromatólise vista nos neurônios pode indicar uma agressão direta (Rech 2007).

Microgliose, células Gitter e neuronofagia ocorrem, pois as células da microglia são as primeiras a reagirem a uma agressão. Estas reações incluem hiperplasia, hipertrofia, fagocitose dos restos celulares e de mielina além de neuroniofagia, ajudando a coordenar os eventos inflamatórios do sistema nervoso central. Quando ocorre necrose do tecido há um influxo de macrófagos derivados de monócitos sanguíneos com fagocitose de restos ricos em lipídeos, estes se tornam macrófagos espumosos denominados também de células Gitter (Zachary 2009) estes eventos em conjunto foram observados em praticamente todos os casos.

As únicas alterações astrocitárias observadas em surtos de intoxicação por selênio foram astrocitose (Costa et al. 2011) e astrócitos tumefeitos (Schultz \& Hoffmann 1995). Em alguns suínos do presente estudo, havia astrócitos com tumefação nuclear, cromatina dispersa e nucléolos proeminentes, denominados então, de astrócitos de Alzheimer tipo II considerando-se que estas células eram negativas na imuno-histoquímica (IHQ) de GFAP e positivas na IHQ para proteína S-100. Células com essas características histológicas e imuno-histoquímicas são descritas em casos de encefalopatia hepática em equinos (Bandarra et al. 2011) e polioencefalomalacia em suínos intoxicados por sal e privação de água (Finnie et al. 2010). A perda seletiva de filamentos de GFAP relacionada na encefalopatia hepática (Summers et al. 1995, Zachary 2009) e na intoxicação por sal (Finnie et al. 2010), podem ser responsáveis pela ausência de marcação na imuno-histoquímica para GFAP. A astrocitose pode ocorrer para reparação do dano tecidual, há aumento e replicação astrocítica e abundante proliferação dos processos celulares astrocíticos contendo filamentos intermediários compostos por GFAP (Zachary 2009), com isso é possível inferir que os animais que possuíram marcação acentuada na IHQ para GFAP estavam em processo de reparação do dano tecidual.

Estágios lesionais finais são caracterizados pelo desaparecimento total de neurônios e neurópilo e os capilares parecem flutuar em meio às células Gitter com áreas de cavitações, a degeneração Walleriana é encontrada nas raízes ventrais (Wilson et al. 1983, Summers et al. 1995). Achado semelhante ocorreu no suíno 8 que apresentou acentuada perda de neurônios, neurópilo, intensa proliferação de cé- 
lulas endoteliais, evidenciadas na IHQ de von Willebrand, lesão em formato de ponte com união entre os cornos ventrais, através da porção ventral da comissura cinzenta na porção cervical da medula. Esse achado também foi encontrado por Davidson-York et al. (1999) nas porções cervicais e lombares em quatro suínos intoxicados por selênio. Astrócitos gemistocíticos observados nesse caso não foram anteriormente descritos em casos de intoxicação por selênio. Essas células são marcadas positivamente na imuno-histoquímica para GFAP e são observadas em casos onde há injuria do parênquima, e onde a reparação ocorrerá por cicatriz glial (Rech 2007, Zachary 2009).

É possível que haja alterações nos níveis de niacina nos casos de intoxicação por selênio, pois ambos os elementos são eliminados via rota de metilação, de maneira que o excesso de selênio induz deficiência de niacina (Wilson et al. 1989) com resultante déficit energético, uma vez que derivados da niacina desempenham funções no metabolismo energético (Nelson \& Cox 2006). A necrose na substância cinzenta das intumescências sugere uma síndrome de privação de energia (Summers et al. 1995), nestes casos, as primeiras células afetadas são os neurônios (Zachary 2009). A vacuolização difusa no citoplasma de neurônios das intumescências, observada nos casos de intoxicação por selênio, pode ser uma resposta inicial dos neurônios ao déficit energético, já que os neurônios motores grandes são responsáveis pela inervação dos membros, exigindo maior aporte energético (Summers et al. 1995).

As alterações histológicas de casco de suínos intoxicados por selênio são pouco relatadas. Leitões recém-nascidos, que tiveram o inicio da intoxicação ainda no interior do útero, apresentaram na região distal da borda coronária focos com degeneração e atrofia sendo revestida por uma fina camada queratina e fendas na derme, além de hiperemia e discreto infiltrado composto por eosinófilos e células mononucleares (Mensink et al. 1990). Com a evolução dos casos notou-se na região distal na borda coronária, ausência de revestimento da derme com acentuado infiltrado composto predominantemente por neutrófilos íntegros e degenerados além de fibrina, fibra vegetal e colônias bacterianas.

\section{REFERÊNCIAS}

Bandarra P.M., Bezerra Júnior P.S., Oliveira L.G.S., Correa G.L.F., Borba M.R., Reck Júnior J., Cruz C.E.F. \& Driemeier D. 2011. Intoxicação experimental por Trema micrantha (Cannabaceae) em equinos. Pesq. Vet. Bras. 31:991-996.

Banholzer E. \& Heinritzi K. 1998. Selenium toxicosis in fattening pigs. J. Anim. Physiol. Anim. Nutr. 80:158-162.

Carson T.L. 2006. Toxic Minerals, Chemicals, Plants and Gases, p.971-984. In: Straw B.E., Mengeling W.L., D’Allaire S. \& Taylor D.J. (Eds), Diseases of Swine. $9^{\text {th }}$ ed. University Press, Ames, Iowa.

Casteel S.W., Osweiler G.D., Cook W.O., Daniels G. \& Kadlec R. 1985. Selenium toxicosis in swine. J. Am. Vet. Med. Assoc. 186:1084-1085.

Casteignau A., Fontán A., Morillo A., Oliveros J.A. \& Segalés J. 2006. Clinical, pathological and toxicological findings of a iatrogenic selenium toxicosis case in feeder pigs. J. Vet. Med. A, Physiol. Pathol. Clin. Med. 53:323326.

Costa R.C., Mesquita L.P., Lopes P.F.R., Santana M.B., Costa L.B., Ferreira E., Varaschin M.S. \& Bezerra Junior P.S. 2011. Intoxicação espontânea por selênio em leitões. Anais 15o Encontro Nacional de Patologia Veterinária (Enapave), Goiânia, GO.
Davidson-York D., Galey F.D., Blanchard P. \& Gardner I.A. 1999. Selenium elimination in pigs after an outbreak of selenium toxicosis. J. Vet. Diagn. Invest. 11:352-357.

De Lahunta A. 2009. Veterinary Neuroanatomy and Clinical Neurology. $3^{\text {rd }}$ ed. W.B. Saunders, Philadelphia. 540p.

Fan A.M. \& Kizer K.W. 1990. Selenium: nutritional, toxicologic and clinical aspects. West. J. Med. 153:160-167.

Finnie J.W., Blumbergs P.C. \& Williamson M.M. 2010. Alzheimer type II astrocytes in the brains of pigs with salt poisoning (water deprivation/ intoxication). Aust. Vet. J. 88:405-407.

Harrison L.H., Colvin B.M., Stuart B.P., Sangster L.T., Gorgacz E.J. \& Gosser H.S. 1983. Paralysis in swine due to focal symmetrical poliomalacia: possible selenium toxicosis. Vet. Pathol. 20:265-273.

Hélie P., Sauvageau R.A. \& Boucher B. 1998. Chronic selenium toxicosis in growing-finishing pigs in southwestern Québec. Can. Vet. J. 39:591-592.

Kim Y.Y. \& Mahan D.C.C. 2001. Comparative effects of high dietary levels of organic and inorganic selenium on selenium toxicity of growing-finishing pigs. J. Anim. Sci. 79:942-948.

Mahan D.C. \& Moxon A.L. 1984. Effect of inorganic selenium supplementation on selenosis in postweaning swine. J. Anim. Sci. 58:1216-1221.

Mensink C.G., Koeman J.P., Veling J. \& Gruys E. 1990. Haemorrhagic claw lesions in newborn piglets due to selenium toxicosis during pregnancy. Vet. Rec. 126:620-622.

Moreno A.M., Sobestiansky J. \& Móres J. 2007. Intoxicação por minerais, produtos químicos, plantas e gases. p.463-486. In: Sobestiansky J. \& Barcellos D. (Eds), Doenças dos Suínos. Cânone Editorial, Goiânia.

Nathues H., Boehne I., Beilage T.G., Gerhauser I. \& Hewicker-Trautwein M. 2010. Peracute selenium toxicosis followed by sudden death in growing and finishing pigs. Can. Vet. J. 51:515-518.

Nelson D.L. \& Cox M.M. 2006. Princípios da Bioenergética, p.485-515. In: Ibid. (Eds), Lehninger - Princípios de Bioquímica. 4⿳ạa ed. Sarvier, São Paulo.

Oliveira K.D., Franca T.N., Nogueira V.A. \& Peixoto P.V. 2007. Enfermidades associadas à intoxicação por selênio em animais. Pesq. Vet. Bras. 27:125-136.

Panter K.E., Hartley W.J., James L.F., Mayland H.F., Stegelmeier B.L. \& Kechele P.O. 1996. Comparative toxicity of selenium from seleno-DL-methionine, sodium selenate, and Astragalus bisulcatus in pgs. Fundam. Appl. Toxicol. 32:217-223.

Penrith M.L. \& Robinson J.T.R. 1996. Selenium toxicosis with focal symmetrical poliomielomalacia in postweaning pigs in South Africa. Onderstepoort. J. Vet. Res. 63:171-179.

Rech R.R. 2007. Alterações no encéfalo de bovinos submetidos à vigilância das encefalopatias espongiformes transmissíveis. Tese de Doutorado em Medicina Veterinária, Universidade Federal de Santa Maria, Santa Maria. 170p.

Sanford S.E. 1990. Selenium toxicosis causing focal symmetrical poliomyelomalacia in pigs. Can. Vet. J. 31:393-394.

Schultz G.L. \& Hoffmann J.E. 1995. Acute feed-related selenium toxicosis in weaner pigs: a case report. Swine Health and Production 3:22-23.

Stowe H.D., Eavey A.J., Granger L., Halstead S. \& Yamini B. 1992. Selenium toxicosis in feeder pigs. J. Am. Vet. Med. Assoc. 201:292-295.

Summers B.A., Cummings J.F. \& De Lahunta A. 1995. Veterinary Neuropathology. Mosby, St Louis. 526p.

Wilson T.M., Scholz R.W. \& Drake T.R. 1983. Selenium toxicity and porcine focal symmetrical poliomyelomalacia: description of a field outbreak and experimental reproduction. Can. J. Comp. Med. 47:412-421.

Wilson T.M., Hammerstedt R.H., Palmer I.S. \& De Lahunta A. 1988. Porcine focal symmetrical poliomyelomalacia: experimental reproduction with oral doses of encapsulated sodium selenite. Can. J. Vet. Res. 52:83-88.

Wilson T.M., Cramer P.G., Owen R.L., Knepp C.R., Palmer I.S., De Lahunta A., Rosenberger J.L. \& Hammerstedt R.H. 1989. Porcine focal symmetrical poliomyelomalacia: test for an interaction between dietary selenium and niacin. Can. J. Vet. Res. 53:454-461.

Zachary J.F. 2009. Sistema Nervoso, p.833-971. In: McGavin M.D. \& Zachary J.F. (Eds), Bases da Patologia em Veterinária. 4aㅡ ed, Elsevier, Rio de Janeiro. 